\title{
Metal stressors consistently modulate bacterial conjugal plasmid uptake potential in a phylogenetically conserved manner
}

\author{
Uli Klümper ${ }^{1,4}$, Arnaud Dechesne ${ }^{1}$, Leise Riber ${ }^{2}$, Kristian K Brandt ${ }^{3}$, Arda Gülay ${ }^{1}$, \\ Søren J Sørensen ${ }^{2}$ and Barth F Smets ${ }^{1}$ \\ ${ }^{1}$ Department of Environmental Engineering, Technical University of Denmark, Lyngby, Denmark; \\ ${ }^{2}$ Department of Biology, University of Copenhagen, Copenhagen, Denmark and ${ }^{3}$ Department of Plant and \\ Environmental Sciences, University of Copenhagen, Frederiksberg, Denmark
}

\begin{abstract}
The environmental stimulants and inhibitors of conjugal plasmid transfer in microbial communities are poorly understood. Specifically, it is not known whether exposure to stressors may cause a community to alter its plasmid uptake ability. We assessed whether metals $(\mathrm{Cu}, \mathrm{Cd}, \mathrm{Ni}, \mathrm{Zn}$ ) and one metalloid (As), at concentrations causing partial growth inhibition, modulate community permissiveness (that is, uptake ability) against a broad-host-range IncP-type plasmid (pKJK5). Cells were extracted from an agricultural soil as recipient community and a cultivation-minimal filter mating assay was conducted with an exogenous $E$. coli donor strain. The donor hosted a gfp-tagged pKJK5 derivative from which conjugation events could be microscopically quantified and transconjugants isolated and phylogenetically described at high resolution via FACS and 16S rRNA amplicon sequencing. Metal stress consistently decreased plasmid transfer frequencies to the community, while the transconjugal pool richness remained unaffected with OTUs belonging to 12 bacterial phyla. The taxonomic composition of the transconjugal pools was distinct from their respective recipient communities and clustered dependent on the stress type and dose. However, for certain OTUs, stress increased or decreased permissiveness by more than 1000-fold and this response was typically correlated across different metals and doses. The response to some stresses was, in addition, phylogenetically conserved. This is the first demonstration that community permissiveness is sensitive to metal(loid) stress in a manner that is both partially consistent across stressors and phylogenetically conserved.
\end{abstract}

The ISME Journal (2017) 11, 152-165; doi:10.1038/ismej.2016.98; published online 2 August 2016

\section{Introduction}

Horizontal gene transfer among bacterial species is recognized as a major evolutionary process (Zhaxybayeva and Doolittle, 2011). Mobile genetic elements can spread across diverse bacterial phyla (Klümper et al., 2015) linking distinct genetic pools (Halary et al., 2009; Norman et al., 2009). A main parameter in assessing the ecology of plasmid transfer is community permissiveness, which refers to the ability of a community to receive a plasmid, both in terms of transfer frequency and transconjugant phylogeny (Musovic et al., 2010).

Correspondence: BF Smets or U Klümper, Department of Environmental Engineering, Technical University of Denmark, Miljøvej 113, 2840 Lyngby, Denmark.

E-mail: bfsm@env.dtu.dk or u.klumper@exeter.ac.uk

${ }^{4}$ Current address: European Centre for Environment and Human Health, University of Exeter, Medical School, Royal Cornwall Hospital, Truro, UK.

Received 4 March 2016; revised 30 May 2016; accepted 7 June 2016; published online 2 August 2016
The spread of plasmid-mediated antibiotic resistance across bacterial communities has recently been identified as a major threat to human health by the WHO (World Health Organization) (WHO, 2014). By carrying sets of genes coding for resistance, conjugal plasmids can facilitate bacterial community adaptation to stress imposed by antibiotics or by other toxicants such as metals and metalloids at elevated concentrations (Sørensen et al., 2005; Heuer and Smalla, 2012).

Here, stress is defined as the exposure of bacteria to a toxicant at a dose that causes a transcriptional response (Cases and de Lorenzo, 2005) as a result of the toxicants incompatibility with normal biological functions (Richardson, 1993). Low exposure levels might act as a stimulant or signal for the transcription of single genes (Pérez-Martín and de Lorenzo, 1996). An elevated dose of the stressor may cause the activation of entire regulons that are part of global stress-response mechanisms. Known stress-responses involve switching to slow growth, biofilm formation or the activation of efflux pumps 
(Mah and O'Toole, 2001). We hypothesize that, additionally, bacterial plasmid uptake potential or individual permissiveness, might increase as a response to stress. This increased permissiveness could either be the direct or indirect effect of an evolutionary evolved stress-response mechanism.

Single strain experiments have shown modulation in gene uptake as a result of stress exposure. In Streptococcus pneumonia, exposure to antibiotics caused increased competence and increased promiscuity toward foreign DNA (Slager et al., 2014). Heat-shock treatment of Gram-positive Corynebacteria enhanced their receipt of an IncP-type plasmid from a Gram-negative E. coli donor, likely due to inactivation of restriction-modification systems (RM) (Schafer et al., 1990). Similarly, in the Gram-negative Pseudomonas putida, pre-exposure to SDS increased its ability to receive and maintain plasmids, possibly by repressing RM systems (Arango Pinedo and Smets, 2005). Cells with a turned-off RM system can become hypersusceptible to foreign DNA or plasmid receipt (Schafer et al., 1990; Corvaglia et al., 2010; Roer et al., 2015). Also, in Bacillus subtilis, sub-inhibitory concentrations of ethanol activated the conjugative transposition of transposon Tn916 (Seier-Petersen et al., 2013) encoding tetracycline resistance (Franke and Clewell, 1981). In contrast, in Escherichia coli, cell-envelope-targeted stress induced the expression of CRISPR-associated (CRISPR-cas) genes which would serve as an intracellular defense against foreign DNA (PerezRodriguez et al., 2011), thus decreasing permissiveness. While these mechanisms are described for specific strains under specific stress conditions, there have been no studies to date that evaluate modulation of permissiveness as a general bacterial stress-response mechanism using complex bacterial communities and multiple stressors.

A typical environmental stress for soil microbes are toxic metals accumulating to elevated concentrations due to agronomic practices, industrial activities or atmospheric deposition (Nicholson et al., 2003; Zhao et al., 2015). Metal toxicity is mainly caused by metal ions disrupting iron-sulfur clusters of metalloenzymes (Macomber and Imlay, 2009; Macomber and Hausinger, 2011; Xu and Imlay, 2012). Metals, at elevated concentrations, have been documented to affect the composition and function of soil bacterial communities (Giller et al., 1998; Gans et al., 2005; Berg et al., 2012), although development of community tolerance is common even when no effects are observed at the levels of activity or community composition (Brandt et al., 2010). Selection for adaptive plasmids within microbial communities has been described as a long-term effect to metal exposure (Campbell et al., 1995; Giller et al., 1998). However, the existence and magnitude of a shortterm effect of metal stress on the permissiveness of bacterial communities remain to be explored.

In this study, we combined a cultivation-minimal assay to measure community-wide permissiveness
(Klümper et al., 2015) with normalized stress exposure to five of the most environmentally relevant metal(oid)s $\left(\mathrm{Cu}^{2+}, \mathrm{Cd}^{2+}, \mathrm{Ni}^{2+}, \mathrm{Zn}^{2+}, \mathrm{AsO}_{3}{ }^{3-}\right)$. This allowed for direct comparison of short-term effects of metal stress on the permissiveness toward the $g f p$ labeled, model broad-host-range IncP-1 $\varepsilon$ plasmid pKJK5 (Bahl et al., 2007) introduced through an E. coli donor strain in a reference soil bacterial community. Plasmid transfer frequencies and the phylogenic composition of the transconjugal pools were compared with corresponding controls to assess stress-induced modulation of permissiveness of the community and of individual community members.

\section{Materials and methods}

\section{Soil sampling}

Soil $(16 \pm 1 \%$ clay, $15 \pm 1 \%$ silt, $43 \%$ fine sand and $26 \pm 1 \%$ coarse sand, with a $\mathrm{pH}\left(\mathrm{H}_{2} \mathrm{O}\right)$ of $\left.7.16 \pm 0.13\right)$ was sampled from unfertilized control plots $(n=3)$ of the CRUCIAL agricultural field site (December 2013, Taastrup, Denmark) (Poulsen et al., 2013; Lekfeldt et al., 2014). Five hundred grams of soil were collected at three locations at each plot from a depth of $5-15 \mathrm{~cm}$. The nine soil samples were pooled, sieved through a $1 \mathrm{~mm}^{2}$ mesh filter, homogenized and stored at $4^{\circ} \mathrm{C}$ for up to one month before conducting the experiments.

\section{Soil bacterial community extraction}

Soil bacterial communities were recovered from $30 \mathrm{~g}$ sub-samples of homogenized soil by Nycodenz (Nycomed Pharmaceuticals, Zürich, Switzerland)extraction (Lindahl and Bakken, 1995). Extracted cells were resuspended in sterile $0.9 \% \mathrm{NaCl}$ solution, filtered, washed, quantified using a Thoma counting chamber (Sigma-Aldrich, St Louis, MO, USA) and adjusted to $10^{7}$ cells per ml to quantify metal-induced stress (measured as growth rate inhibition) or to be used as recipients in the filter mating assay.

\section{$\left[{ }^{3}\right.$ H]leucine incorporation inhibition assay}

A $\left[{ }^{3} \mathrm{H}\right]$ leucine incorporation assay (Supplementary Text 1) was used to estimate the concentrations of individual metal(loid)s inhibiting soil bacterial growth rates by $20 \%\left(\mathrm{IC}_{20}\right)$ and $50 \%\left(\mathrm{IC}_{50}\right)$, respectively (Lekfeldt et al., 2014). The experimental data linking leucine incorporation to metal dose were fitted with a four parameter log-logistic doseresponse curve using the drc (Analysis of DoseResponse Curves) package for $\mathrm{R}$ (Knezevic et al., 2007) (Supplementary Figure 1).

Plasmid and donor strain

Cells of E. coli MG1655::IacI ${ }^{q}-p L p p-m C h e r r y-K^{R}$ (Klümper et al., 2015) carrying the IncP-1e broadhost range plasmid pKJK5::gfpmut3b (Bahl et al., 2007) were used as donors. Plasmid pKJK5 has an 
extremely broad transfer range, including both Gram-negative and Gram-positive phyla (Klümper et al., 2015). In addition, pKJK5 does not encode metal-related resistance mechanisms (Bahl et al., 2007).

The plasmid was marked with an entranceposonderived (Bahl et al., 2009) genetic tag that carries a $\mathrm{LacI}^{q}$ repressible promoter upstream the conditionally expressed gfpmut3b gene, encoding the green fluorescent protein (GFP). The plasmid donor strain was chromosomally tagged with a gene cassette encoding constitutive red fluorescence, expressed by the mCherry gene, and constitutive $\operatorname{lacI}^{q}$ production. As a result, $g f p$ expression is repressed in the donor strain, but on successful conjugal transfer to a soil bacterium, plasmid-encoded gfp expression is de-repressed, resulting in green fluorescent cells or microcolonies, which can be retrieved by fluorescence-activated cell sorting (FACS) or detected by fluorescence microscopy, respectively (Sørensen et al., 2005; Klümper et al., 2015). The donor strain was grown overnight in LB medium supplemented with trimethoprim $\left(30 \mu \mathrm{g} \mathrm{ml}^{-1}\right)$, harvested by centrifugation, washed in $0.9 \% \mathrm{NaCl}$ solution, adjusted in cell density $\left(\mathrm{OD}_{600}\right)$ and used in filter mating assays as described previously (Klümper et al., 2014a). The viability and plasmid transfer ability of the donor strain under all metal stress conditions were verified in control mating assays with an untagged E. coli MG1655 recipient through microscopic observations.

\section{Filter matings}

The extracted soil bacterial community was challenged with the exogenous plasmid via solid-surface filter matings (Musovic et al., 2010; Klümper et al., 2014a) to maximize cell-to-cell contact, as physical barriers would limit the contact between freshly introduced plasmid donors and potential recipients in an intact soil matrix (Dechesne et al., 2005). Compared with the original protocol (Klümper et al., 2014a) the initial ratio of donor to recipient cells was increased to $10: 1$ to maximize recipient cell/microcolony contact with the donor cells during the $48 \mathrm{~h}$ incubation period.

Filters were placed on an agar-solidified $10 \%$ soil extract medium after Musovic et al. (2010). The limited amount of nutrients resulted in monolayer cell coverage of the filter after $48 \mathrm{~h}$ as confirmed with confocal laser scanning microscopy (CLSM). With an initial density of $\sim 300000$ cells per $\mathrm{mm}^{2}$ and assuming an average cell surface area of $1 \mu^{2}$, the average number of cell doublings per inoculated cell during incubation was thus estimated at $<5$.

Filter matings were performed on medium without metal amendment (controls) or supplemented with $\mathrm{CuSO}_{4}, \mathrm{NiSO}_{4}, \mathrm{ZnSO}_{4}, \mathrm{CdCl}_{2}$ or $\mathrm{Na}_{2} \mathrm{HAsO}_{3}$ at concentrations corresponding to $\mathrm{IC}_{20}$ and $\mathrm{IC}_{50}$ based on $\left[{ }^{3} \mathrm{H}\right]$ leucine incorporation of the recipient community. Filters were incubated for $48 \mathrm{~h}$ at $25^{\circ} \mathrm{C}$, before $72 \mathrm{~h}$ storage at $4^{\circ} \mathrm{C}$ for GFP maturation. Conjugation events were checked by epifluorescence stereomicroscopy and CLSM (Musovic et al., 2010).

\section{Transfer frequency quantification}

Conjugation events were visualized by stereomicroscopy and quantified by automated image analysis (Image Pro Plus 7.1; Media Cybernetics, Silver Spring, MD, USA) (Supplementary Text 1) as previously described (Musovic et al., 2010; Klümper et al., 2014b). The number of detected transfer events was scaled up to the total filter area and transfer frequency was calculated by dividing by the number of originally added recipient cells (Supplementary Figure 2).

\section{FACS and sequencing}

For each mating condition, cells from triplicate filters were combined in $2 \mathrm{ml} 0.9 \% \mathrm{NaCl}$ solution and detached by vortexing at 3000 r.p.m. for $30 \mathrm{~s}$. Transconjugant cells and recipient community were sorted using FACS (Supplementary Text 1, Supplementary Figure 2). Gating and sorting of transconjugants for each of the combinations were performed based on bacterial size, green fluorescence and exclusion of red fluorescent donor cells as described earlier (Klümper et al., 2015).

Recipient community cells were sorted from the same samples using the same conditions, including both colorless recipient and green fluorescent transconjugal cells and excluding red fluorescent donor cells. In all cases, a minimum of $20000 \mathrm{gfp}$ expressing transconjugal cells or recipient cells were sorted. Sorted bacterial cells were collected, lysed and subject to tag-encoded 16s rRNA amplicon sequencing (Supplementary Text 1) (Klümper et al., 2015).

\section{Sequence analysis}

All sequences documented in this study were deposited in the European Nucleotide Archive under study accession number PRJEB13628.

Sequence analysis was carried out using mothur v.1.32.1 (Schloss et al., 2009) and the MiSeq SOP (Kozich et al., 2013) as accessed on 1 December 2014 from http://www.mothur.org/wiki/MiSeq SOP. Sequences were classified based on the RDP classifier (Wang et al., 2007).

Diversity was assessed based on observed operational taxonomic units (OTUs) at 97\% sequence similarity. Phylogenetic trees were constructed using iToL (http://itol.embl.de/; Letunic and Bork, 2007).

NMDS plots showing the phylogenetic distance between samples were produced based on the theta Yue Clayton dissimilarity index (Yue and Clayton, 2005) using mothur software and clustering of samples was tested for significance by analysis of molecular variance (AMOVA) (Excoffier et al., 1992). Based on NMDS clustering and because the number 
of replicates per condition differed, replicates were combined for subsequent statistical analysis.

\section{OTU-level permissiveness analysis}

At the community level, precise estimates of initial recipient abundance $(R)$ and number of conjugation events $(T)$ made it possible to measure permissiveness accurately. This was impossible at the OTU level, where only relative abundances of an OTU in the recipient community (after mating incubation) and in the transconjugal pool were measured (Supplementary Figure 2). These values are not solid estimators of the initial recipient abundance or of the number of conjugation events for a specific OTU as they are affected by the growth rate of that OTU relative to other OTUs, the possibility of multiple transfers within an OTU microcolony, and the permissiveness of other recipients. Increases or decreases in recipient OTU cell densities during the mating incubations per se (that is, due to a competitive advantage or disadvantage compared with other OTUs) are possible, but equivalent effects would hold for the transconjugant cell densities of that OTU, as the pKJK5 plasmid does not encode for any growthbeneficial phenotype. Hence, an apparent OTU-level permissiveness (AP) can be calculated, based on the relative recipient and transconjugant abundances at the end of the mating incubation:

$A P_{i}=\frac{\text { rel. abundance in transconjugal pool of OT } U_{i}}{\text { rel. abundance in recipient community of OTU } U_{i}}=\frac{T_{i}}{R_{i}}$

Although this apparent permissiveness is not only affected by transfer, but also by the fact that multiple transfers can occur in a microcolony and by recipient and transconjugant growth; these phenomena are expected to occur both under the reference and the metal stress conditions. We therefore use the ratio $(\delta)$ of an OTU's apparent permissiveness under stress $\left(\mathrm{AP}_{\mathrm{i}}\right.$ stress $)$ and reference conditions $\left(\mathrm{AP}_{\mathrm{i}}\right.$ ref $)$ to describe stress-induced permissiveness changes in that OTU:

$\delta_{i}=\frac{\mathrm{AP}_{i \text { stress }}}{\mathrm{AP}_{i \text { ref }}}=\frac{T_{i \text { stress }} / R_{i \text { stress }}}{T_{i \text { ref }} / R_{i \text { ref }}}$

If the stress has no effect on an OTU's permissiveness, $\delta$ would be equal to 1 while values above or below 1 would indicate an increase or decrease in permissiveness under the stress condition, respectively.

To analyze whether the variability of $\delta$-values was phylogenetically conserved, we created a maximum likelihood tree of the dominant (average relative abundance in all transconjugal pools $>0.05 \%$ ) transconjugal OTUs based on similarity of their $\delta$ values across stresses. Phylogenetic conservation of permissiveness response for each stress condition was tested using the analysis of trait module of Phylocom v4.2 (Webb et al., 2008).

Exploratory statistics were carried out in $\mathrm{R}$ using the package car (Companion to Applied Regression, version 2.0-25). The package psych (Revelle, 2014) was used to calculate Spearman correlations between parameters and test their significance, after adjusting the $P$-values for multiple testing (Hommel, 1988).

\section{Results}

Metal stress reduces transfer frequencies more than metabolic activity

Inhibitory metal concentrations $\left(\mathrm{IC}_{20}\right.$ or $\left.\mathrm{IC}_{50}\right)$ applied in the mating experiments were determined by doseresponse modeling of $\left[{ }^{3} \mathrm{H}\right]$ leucine incorporation data (Supplementary Figure 1). Molar metal toxicity increased in the order (Table 1): $\mathrm{AsO}_{3}{ }^{3-}<\mathrm{Zn}^{2+}<\mathrm{Cd}^{2+}$ $<\mathrm{Cu}^{2+}<\mathrm{Ni}^{2+}$. Matings conducted with metal stress will subsequently be identified with a combination of the elemental symbol and the inhibitory level (for example, As20 see Table 1) and compared with the non-stressed reference condition.

Conjugation events were detected as green fluorescent cells and microcolonies in microscopic images of the filter matings. Red fluorescent donor cells were detected in all matings, albeit with a slight decrease in density under stress conditions (Figure 1). Flow cytometric counts of intact red fluorescent donor cells confirmed that donor cell counts exceeded total recipient counts under each condition to ensure that each recipient microcolony was in contact with multiple donor cells.

Conjugation events were detected at $\sim 1$ in 15000 $\left(6.8 \times 10^{-5} \pm 3.8 \times 10^{-5}\right)$ of the initial soil recipient bacterial cells under reference conditions. This frequency decreased under stress conditions for all metals (Figure 1). Community permissiveness significantly decreased $(P<0.05)$ under conditions of metal stress in a dose-dependent manner (Figure 2). This decrease was metal specific and was more severe than the effect of the metal on community-wide metabolic activity (Table 1, Figure 2). Cu50, Zn50 (both $>90 \%$ reduction) and Cd50 (no transfer detected) caused the largest permissiveness reduction.

Reduction in community permissiveness could result from a general decrease of transfer across all taxa or from taxon-specific modulation of individual permissiveness. We FACS-sorted at least 20000 transconjugant cells from each mating, which were

Table 1 Inhibitory concentrations causing $20 \%\left(\mathrm{IC}_{20}\right)$ and $50 \%$ $\left(\mathrm{IC}_{50}\right.$ ) bacterial growth inhibition as inferred by dose-response modeling of $\left[{ }^{3} \mathrm{H}\right] l$ leucine incorporation data (Supplementary Figure 1)

\begin{tabular}{lrlrl}
\hline Metal & \multirow{2}{*}{$I C_{20}(\mu M)$} & & $I C_{50}(\mu M)$ & \\
\hline $\mathrm{AsO}_{3}{ }^{3-}$ & 40.5 & $($ As20) & 125.2 & (As50) \\
$\mathrm{Cd}^{2+}$ & 12.6 & $(\mathrm{Cd} 20)$ & 63.6 & (Cd50) \\
$\mathrm{Ni}^{2+}$ & 3.7 & $(\mathrm{Ni20})$ & 11.5 & (Ni50) \\
$\mathrm{Zn}^{2+}$ & 24.7 & $(\mathrm{Zn20})$ & 80.7 & (Zn50) \\
$\mathrm{Cu}^{2+}$ & 6.9 & $(\mathrm{Cu} 20)$ & 28.9 & (Cu50) \\
\hline
\end{tabular}

Treatment names used throughout this paper are indicated in brackets. 

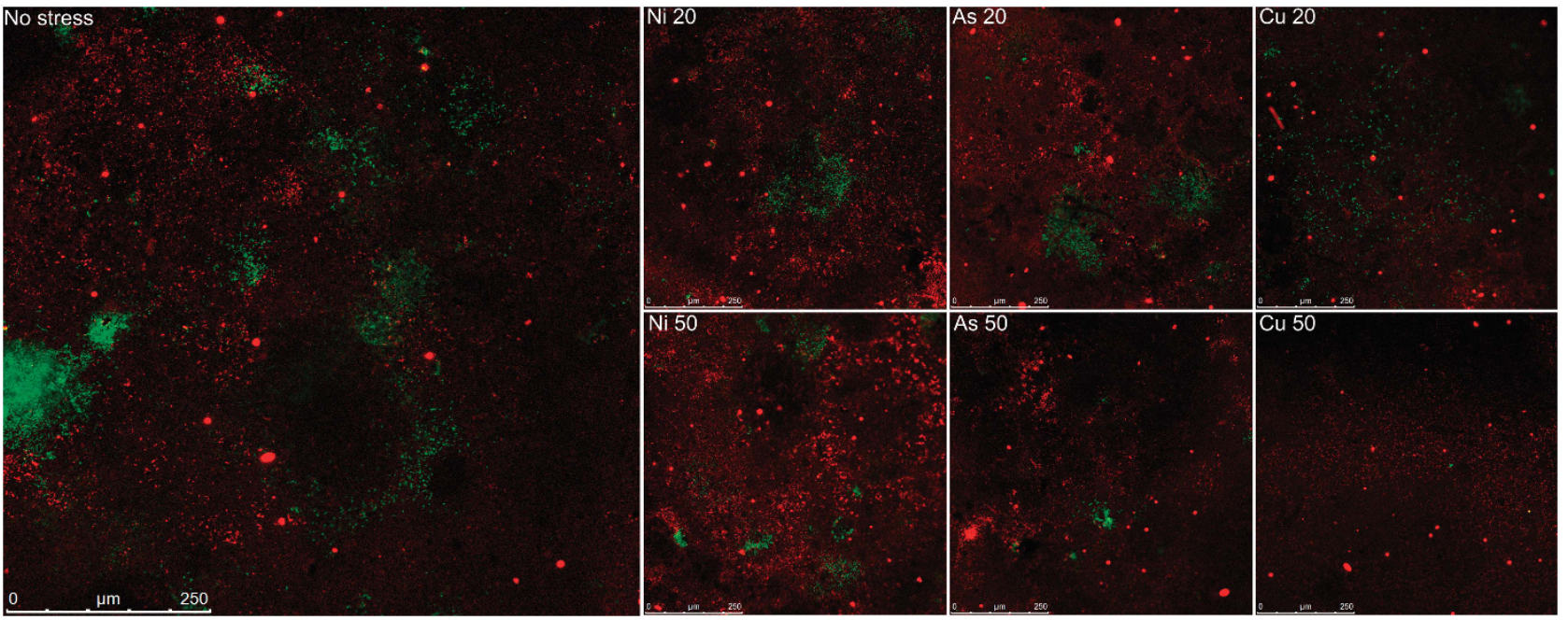

Figure 1 Images of plasmid transfer from the E. coli MG1655 donor strain to soil bacteria at reference condition (no stress) (left panel) or as affected by metal stress. Type of metal (Ni, As or $\mathrm{Cu}$ ) and degree of stress are indicated in the top left corner of the other panels; number refers to \% inhibition of $\left[{ }^{3} \mathrm{H}\right]$ leucine incorporation for the Nycodenz-extracted recipient bacterial community. Donor bacteria, chromosomally tagged with mCherry appear red, recipient bacteria appear initially colorless until successful plasmid receipt and subsequent gfp expression, transconjugants appear green.

subjected to $16 \mathrm{~S}$ rRNA amplicon sequencing to analyze their phylogenetic composition.

All transconjugal pool sequence libraries showed coverage above $98 \%$, and no subsampling effect was found at a depth 50,000 sequences. Ten subsampled sets of each sample showed no significant dissimilarity $(P>0.99)$ based on weighted UNIFRAC comparisons when compared with the original sequencing library. Thus, further analysis of transconjugal pools was done at a subsampling depth of 50000 sequences.

Diversity of transconjugal pools is maintained in spite of transfer frequency reduction

We report an extremely diverse phylogenetic range of transconjugants. Across all pools, 206 permissive OTUs, distributed over 12 phyla, were identified (Figure 3a). These included the dominant Proteobacteria ( $\alpha, \beta, \gamma$ and $\delta$ ) and Bacteroidetes (Figure $3 b$ ), as well as other Gram-negative phyla (Acidobacteria, Nitrospira, Fusobacteria, Planctomycetes, Gemmatimonadetes and Verrucomicrobia), diverse Gram-positive phyla (Firmicutes, Actinobacteria and Chloroflexi) and the candidate phylum Cand. Saccharibacteria.

Plasmid transfer was detected both in abundant and rare taxa of the initial recipient community (Figure 3a). The phylogenetic composition of all transconjugal pools was similar at the phylum level (Figure 3b). The only exception was As50, where the Bacteroidetes phylum was nearly absent from the transconjugal pool, in spite of its abundance in the corresponding recipient community after incubation. Larger shifts were identified in the less abundant phyla with Gram-positive Firmicutes (Figure 3b) and Actinobacteria (Figure 3C, Supplementary Table 2)

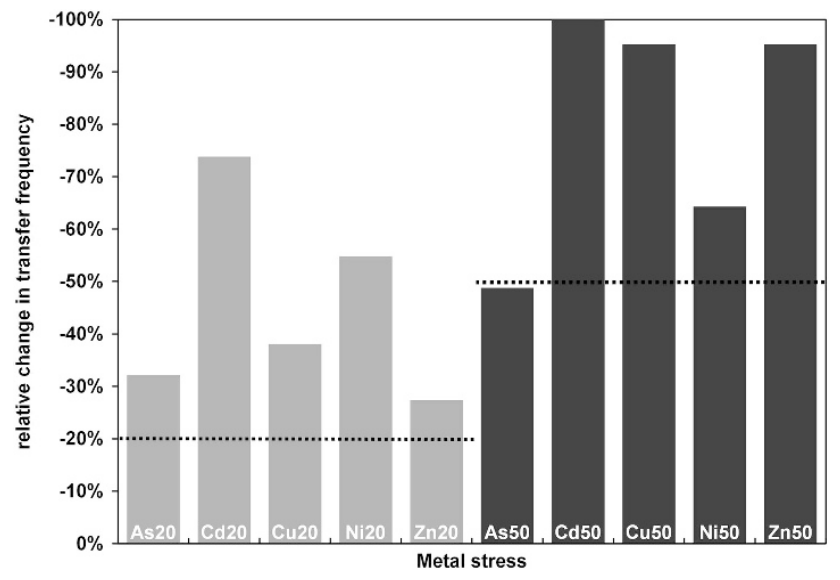

Figure 2 Reduction of pKJK5 transfer frequency under metal stress conditions as compared with the reference condition $(0 \%$ value). Type of metal (As, Cd, Cu, Ni or $\mathrm{Zn}$ ) and degree of stress are indicated on individual bars; numbers refer to inhibitory concentrations decreasing $\left[{ }^{3} \mathrm{H}\right]$ leucine incorporation rates of the recipient bacterial community by $20 \%$ ( $\mathrm{IC}_{20}$, gray bars) and $50 \%$ ( $\mathrm{IC}_{50}$, black bars). Plasmid transfer frequencies were calculated based on analysis of 90-150 images per condition.

increasing in richness and up to eightfold in abundance under several stress conditions.

The average richness ( $\alpha$-diversity) of the transconjugal pools was $196.0 \pm 14.4$ OTUs, irrespective of transfer frequency reduction (Figure 4). While $38.5 \pm 2.2 \%$ of the recipient community OTUs (identified after $48 \mathrm{~h}$ incubation) were permissive to pKJK5 under reference conditions, this increased to $57-96 \%$ under metal stress (Figure 4). This increase resulted from a dramatic ( $>50 \%, P=0.0053)$ decrease in the recipient community richness under metal stress conditions. As $94-97 \%$ of the transconjugal sequences under metal stress conditions 


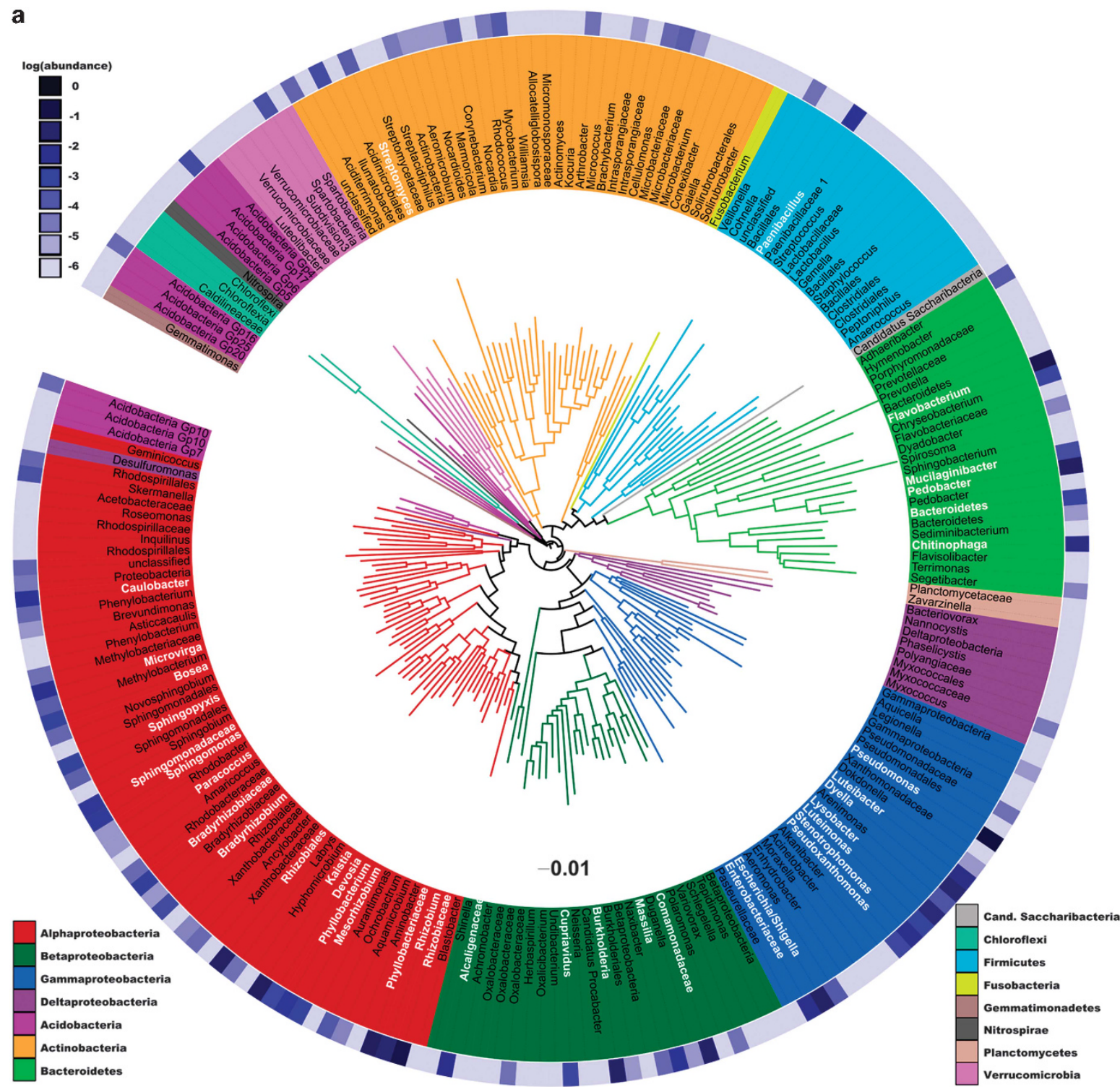

b

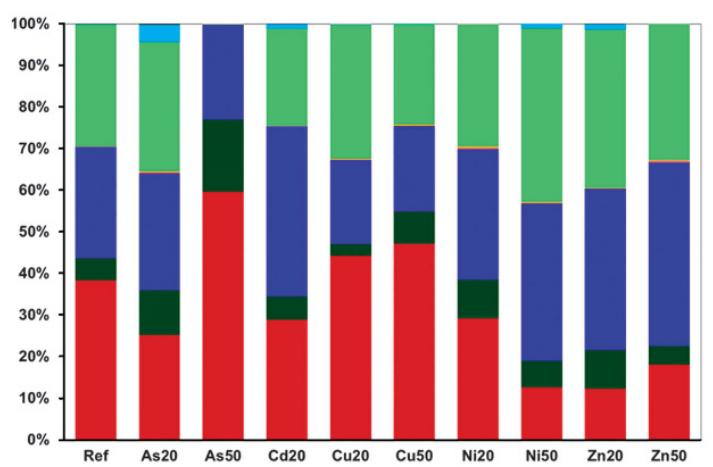

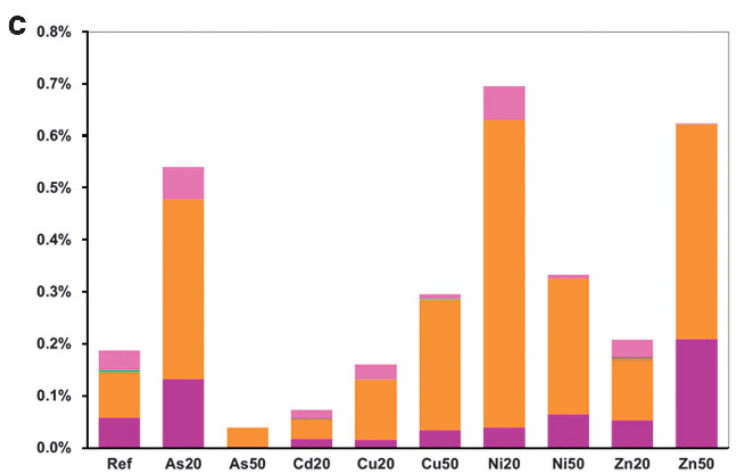

Figure 3 Phylogenetic composition of transconjugal pools. (a) Phylogenetic tree showing all 206 identified transconjugal OTUs. Colors of the branches mark different phylogenetic groups. The 38 most abundant OTUs $(>0.05 \%$ relative abundance across all pools), used in subsequent OTU permissiveness analysis are shown in white letters. The blue heatmap-circle at the periphery of the tree represents logtransformed relative OTU abundance in the reference recipient community. (b) Phylogenetic composition of the transconjugal pools obtained at various stress conditions. (c) Relative abundance of rare phyla $(<1 \%$ mean relative abundance) in transconjugal pools for the various stress conditions. Experimental treatments (type of metal and degree of stress) are indicated below the bars for $\mathbf{b}$ and $\mathbf{c}$; numbers refer to inhibitory concentrations decreasing $\left[{ }^{3} \mathrm{H}\right]$ leucine incorporation rates of the recipient bacterial community by $20 \%\left(\mathrm{IC}_{20}\right)$ and $50 \%$ $\left(\mathrm{IC}_{50}\right)$. 'Ref' denotes reference condition (unstressed control). 


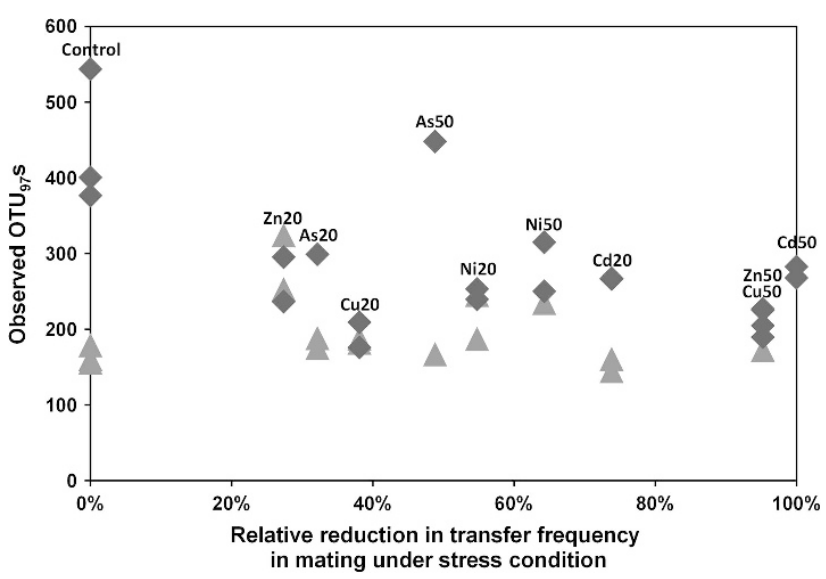

Figure 4 Observed number of unique operational taxonomic units (OTUs; 97\% sequence similarity) as a function of reduction in plasmid transfer frequency caused by metal stress. The OTU richness of the transconjugal pools (triangles) and the corresponding sorted soil recipient communities (diamonds) is shown. Experimental treatments (type of metal and degree of stress) are indicated; numbers refer to inhibitory concentrations decreasing $\left[{ }^{3} \mathrm{H}\right]$ leucine incorporation rates of the recipient bacterial community by $20 \%\left(\mathrm{IC}_{20}\right)$ and $50 \%\left(\mathrm{IC}_{50}\right)$.

belonged to OTUs also found in the reference transconjugal pool, the OTUs permissive to pKJK5 survived better under metal stress than the nonpermissive OTUs. However, 86 additional OTUs, rare in abundance, were exclusively detected in transconjugal pools under metal stress conditions.

Transconjugal pools cluster according to stress The overall OTU richness and phylum level composition of the transconjugal pools remained unchanged under most stress conditions. However, at the OTU level their phylogenetic composition was significantly altered by stress. Some OTUs in the recipient communities were not permissive to plasmid pKJK5 under any of the tested conditions and were excluded prior to ordination (Figure 5). Transconjugal pools nevertheless clustered significantly apart from their respective recipient communities (AMOVA test, $P<0.001$ ).

Replicate transconjugal pools and recipient communities consistently grouped together dependent on the type and degree of the metal stress. Three main clusters were observed among the transconjugal pools (Figure 5). Cluster I, comprised of the Cu50, Cd20, Ni20 and Ni50 replicate pools, grouped significantly apart $(P<0.001)$ from the reference transconjugal pools. Replicate transconjugal pools of $\mathrm{Cu} 20$ formed a separate Cluster II with a phylogenetic composition significantly different $(P<0.05)$ from pools obtained at any other stress condition. By contrast, the transconjugal pools of As20, As50 and Zn20 did not significantly shift in phylogenetic composition compared with the reference pool $(P>0.05)$, with which they formed Cluster III.

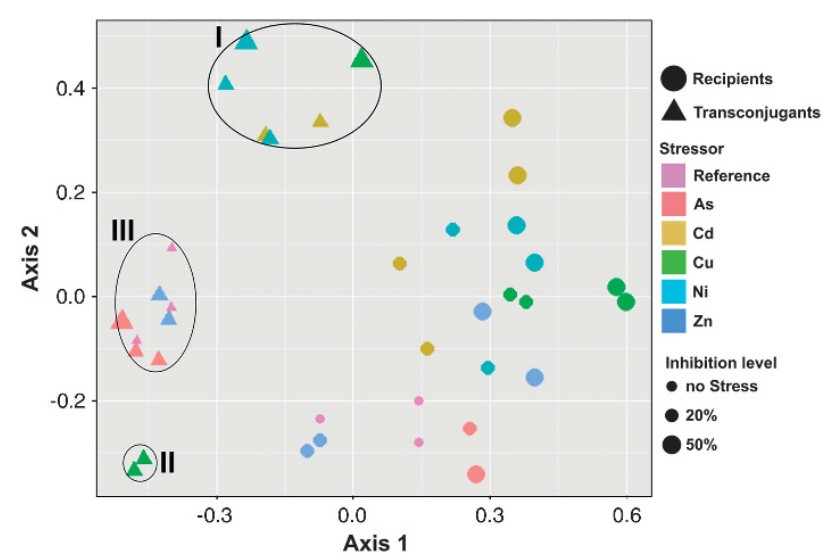

Figure 5 Non-metric 2-dimensional scaling analysis (NMDS) revealing distinct clustering of transconjugal pools (circles) and recipient communities (triangles). Three transconjugal clusters are identified and named with roman numerals. Experimental treatments (type of metal and degree of stress as operationally defined by $\%$ inhibition of $\left[{ }^{3} \mathrm{H}\right]$ leucine incorporation rates) are shown by color and size of symbols. Amplicon pools were subsampled at 50000 sequences. OTUs from the recipient pool that were not represented in any transconjugal pool were removed prior to subsampling and ordination based on weighted OTU abundance using the Theta Yue Clayton (Yue and Clayton, 2005) algorithm.

\section{Stress-specific responses at OTU level are resolved by} transconjugal taxonomy

The relative abundance of transconjugal OTUs varied across metal treatments (Figure 5). Two factors may have caused these variations: a metalspecific shift in the composition of the recipient community or a metal-specific modulation in the permissiveness of some OTUs. We investigated whether the second mechanism, that is, modulation of OTU permissiveness, could be detected. Hence, we analyzed, for each of the 38 dominant transconjugal OTUs (Figure 3), the change in permissiveness $(\delta)$ between the stressed conditions and the unstressed reference.

For some OTUs, under certain stress conditions, permissiveness increased over 1000-fold or decreased up to 10000 fold (Figure 6). The permissiveness of a high number of OTUs (138 of 342 tested combinations) increased or decreased more than 10-fold in response to stress. Under some conditions (As20, Cu20, Cu50, Ni20 and Zn20), permissiveness increased slightly for most of the OTUs (Supplementary Figure 4). In contrast, arsenic at high concentration slightly decreased the permissiveness of the majority of the OTUs.

Individual OTUs tended to respond in a consistent manner to different metal stresses. Of 15 pairwise correlations of the $\delta$-values between the metal stresses (Cd20, Cu20, Cu50, Ni20, Ni50 and Zn20), 12 were significant $(P<0.05)$ (Figure 6). The $\delta$-values for Zn50 correlated poorly with the others, except for Ni20, mainly caused by few Rhizobiales OTUs with a highly decreased permissiveness. The metalloid arsenic at As50 did not correlate well with the metals; here all OTUs belonging to the Bacteroidetes phylum displayed a strong decrease in permissiveness (Figure 6). Despite a general consistency across most 


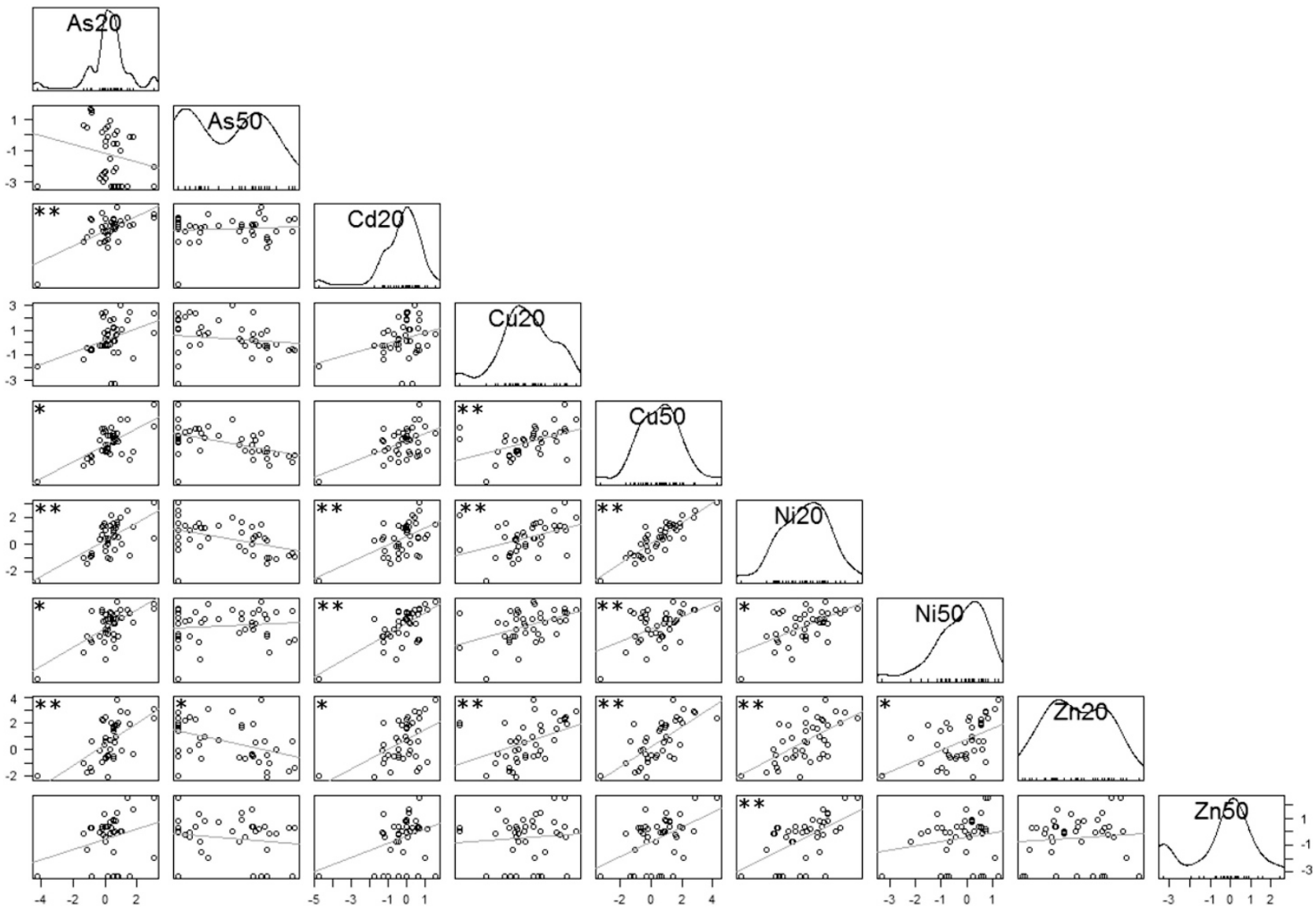

Figure 6 Pairwise correlation analysis of the modulation of the permissiveness $(\log (\delta))$ across metal treatments for all 206 bacterial OTUs to explore whether two stress conditions resulted in similar response. Each circle symbol in the diagrams corresponds to one OTU plotted according to its $\log (\delta)$ under the two compared conditions. Lines show linear regression. Star(s) in the top left corner indicate the significance of the Spearman correlation $\left({ }^{*} P<0.05,{ }^{*} P<0.005\right)$ after correction for multiple testing (Hommel, 1988). Experimental treatments (type of metal and degree of stress) are indicated with numbers referring to inhibitory concentrations decreasing $\left[{ }^{3} \mathrm{H}\right]$ leucine incorporation rates of the recipient bacterial community by $20 \%\left(\mathrm{IC}_{20}\right)$ and $50 \%\left(\mathrm{IC}_{50}\right)$.

metal stresses, almost none of the 38 most abundant OTUs responded similarly to all stress conditions (Figure 7). Only one OTU, a member of the alphaproteobacterial Rhodobacteriales family, responded to every applied stress with a significant decrease in plasmid uptake (always $>100$ fold and up to 5000 fold) (Figure 7).

Phylogenetically similar OTUs responded similarly to metal stress. All Bacteroidetes OTUs responded similarly to the metal exposure: for all stresses except As50, the plasmid uptake ability of the OTUs belonging to the Bacteroidetes phylum increased by $>10$-fold (Figure 7). The only Gram-positive OTU among the 38 most abundant transconjugant OTUs, a member of the Firmicutes phylum, responded in a similar way. For most of the transconjugal OTUs in the phylum Proteobacteria, the stress response was more variable. Four of these OTUs, similar to Bacteroidetes, became increasingly permissive under stress conditions. Especially an OTU classified as Xanthomonadales responded with an increased permissiveness to most stresses and showed the highest relative increase in permissiveness $(>1000$ fold for Cu50). Most Alphaproteobacteria, such as the
Rhizobiales, displayed little permissiveness modulation under stress conditions.

The distribution of $\delta$-values across the community's phylogenetic tree was significantly correlated with OTU phylogeny $(P<0.05)$ for two $(\mathrm{Zn} 20, \mathrm{Ni20})$ of the nine stress conditions and additionally showed a tendency for phylogenetic conservation $(P=0.074-0.258)$ for six of the remaining seven conditions (Supplementary Table 1).

\section{Discussion}

Broad-host range plasmids introduced to microbial communities can spread among a wide variety of Gram-negative and Gram-positive bacterial species (De Gelder et al., 2005; Musovic et al., 2014; Shintani et al., 2014; Klümper et al., 2015). Here we demonstrate pKJK5 transfer to an extremely diverse fraction of a soil bacterial community both under reference and metal stressed conditions. The transconjugant pool included abundant, as well as rare species-level OTUs and covered 12 different phyla, thereby expanding the realized transfer range of IncP-type 

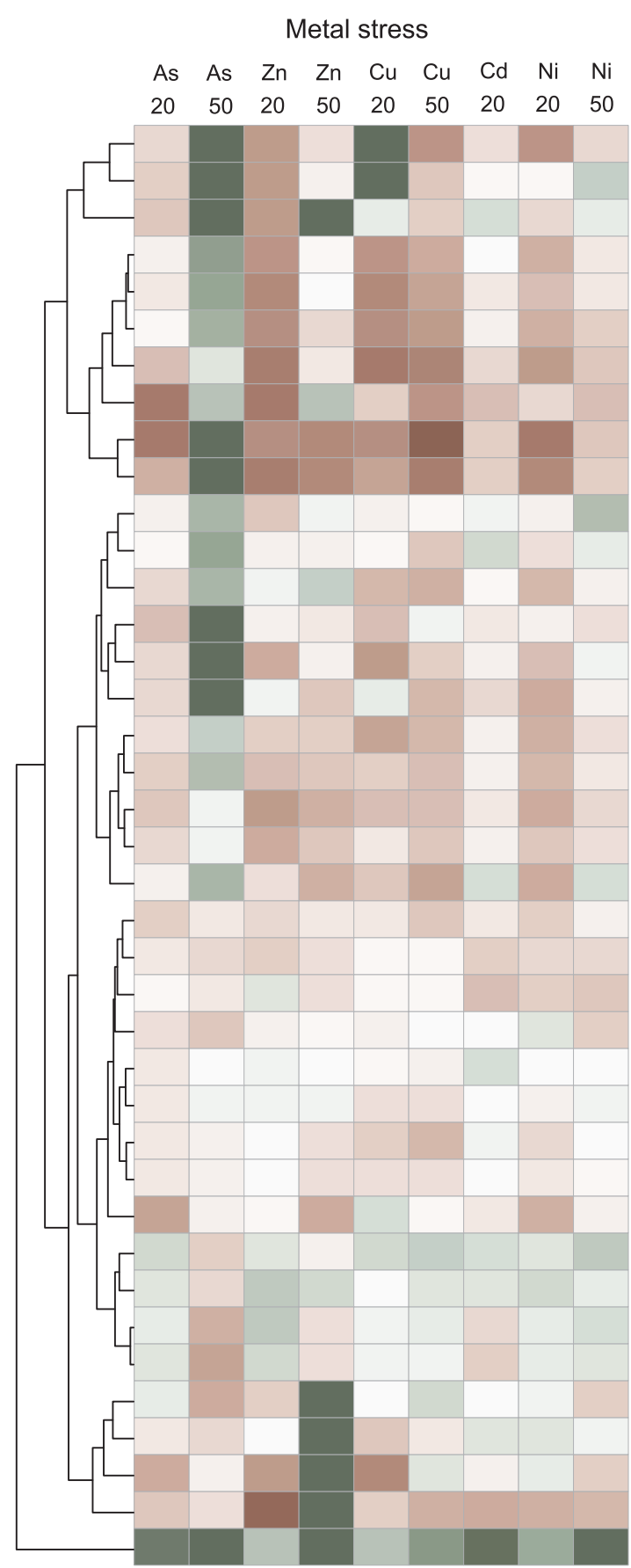

Sphingobacteriales

Sphingobacteriales

Burkholderiales ( $\beta$ )

Sphingobacteriales

Sphingobacteriales

Flavobacteriales

Enterobacteriales $(\gamma)$

Bacillales

Xanthomonadales $(\gamma)$

Sphingomonadales $(\alpha)$

Unclassified

Xanthomonadales $(\gamma)$

Rhizobiales $(\alpha)$

Rhizobiales $(\alpha)$

Sphingomonadales $(\alpha)$

Rhizobiales ( $\alpha$ )

Sphingomonadales $(\alpha)$

Xanthomonadales $(\gamma)$

Caulobacterales $(\alpha)$

Burkholderiales ( $\beta$ )

Xanthomonadales $(\gamma)$

Burkholderiales $(\beta)$

Pseudomonadales $(\gamma)$

Xanthomonadales $(\gamma)$

Burkholderiales $(\beta)$

Rhizobiales $(\alpha)$

Rhizobiales $(\alpha)$

Actinomycetales

Rhizobiales ( $\alpha$ )

Xanthomonadales $(\gamma)$

Rhizobiales $(\alpha)$

Rhizobiales $(\alpha)$

Rhizobiales $(\alpha)$

Rhizobiales $(\alpha)$

Rhizobiales $(\alpha)$

Rhizobiales $(\alpha)$

Burkholderiales ( $\beta$ )

Enterobacteriales $(\gamma)$

Rhodobacterales $(\alpha)$

\section{Average \\ abundance \\ in T-pools}
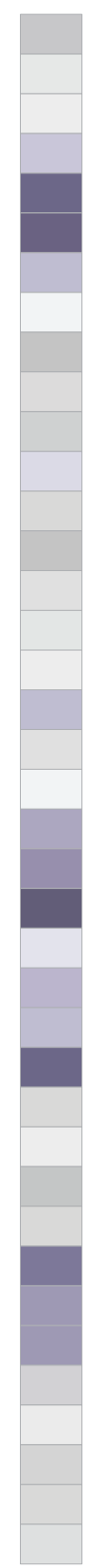

Bacteroidetes

Proteobacteria

Firmicutes

Actinobacteria

Figure 7 Maximum likelihood tree clustering of the 38 most abundant OTUs in the transconjugal pools (relative average abundance $>0.05 \%$ ) based on similarity in their changes in permissiveness under different stress conditions. The heatmap shows the relative change in permissiveness ( $\delta$ value) of each OTU: an increased plasmid receipt response is shown in red, and a decreased one in green. The average relative abundance of an OTU across all transconjugal pools is shown in violet (right). Their taxonomy is indicated by the color of the font (for Proteobacteria, the class is shown in brackets). Experimental treatments (type of metal and degree of stress) are indicated above the heatmap with numbers referring to inhibitory concentrations decreasing $\left[{ }^{3} \mathrm{H}\right]$ leucine incorporation rates of the recipient bacterial community by $20 \%\left(\mathrm{IC}_{20}\right)$ and $50 \%\left(\mathrm{IC}_{50}\right)$. 
plasmids in soil beyond our previous observations with two more phyla, Nitrospira and Cand. Saccharibacteria (Klümper et al., 2015). About 86 transconjugant OTUs were only detected under specific stress conditions, which might stem from a stimulation of permissiveness in these OTUs associated with metal stress exposure. Because of the low abundance of these rare OTUs $(<0.01 \%$ rel. abundance) this possibility requires confirmation.

More importantly, we show, for the first time, that metal stress can modulate - increase or decrease the permissiveness of different members of a soil bacterial community toward an IncP plasmid. Elevated levels of plasmids and plasmid-encoded genes have been reported in soil communities subject to long-term anthropogenic selective pressure through agricultural use (Agersø et al., 2006; Heuer et al., 2011; You et al., 2012), and exposure to long-term metal stress was shown to increase plasmid mobilization capacity of a soil community (Top et al., 1995). However, these long-term effects offer no direct evidence for increased permissiveness toward plasmids because they may also be caused by indirect selection of specific beneficial phenotypes. By employing a plasmid (Bahl et al., 2009) that does not encode a beneficial phenotype when exposed to the chosen stressors and examining transfer directly, we aim at effectively uncoupling plasmid transfer from selective forces.

While earlier studies revealed that the plasmid uptake of individual strains can differ under stress conditions (Arango Pinedo and Smets, 2005; Slager et al., 2014), this is the first assessment of OTU permissiveness in a community context. Taking advantage of our high-resolution approach, we demonstrated that stress-induced modulation of permissiveness is indeed unique for each OTU.

The composition and density of the transconjugal pools is affected by (1) transconjugant growth and (2) de novo transconjugant formation by plasmid transfer to recipient cells. Both processes can be affected by heavy metal exposure. While we employ a cultivation-minimal assay with a highinitial bacterial density on the filters, growth may occur on the filters. However, transconjugant cells are expected to grow at the same rate as recipient cells of the same OTU, as pKJK5 plasmid carriage does not selectively affect growth. An artefactual underestimation of $T / R$ due to recipient growth is, therefore, unlikely as similar growth is expected for the respective transconjugant. An overestimation of $T / R$, due to transfer occurring before die-off of heavy-metal-sensitive recipient OTUs, is unlikely as transfer can only be detected in transconjugant cells that maintain sufficient metabolic activity to ensure GFP production. Hence, $T$-to- $R$ ratios can be compared across treatment conditions, to evaluate permissiveness differences across OTUs.

Artificial permissiveness changes could be inferred if the abundance of non-participatory (those with zero permissiveness) recipient OTUs would dramatically increase or decrease due to selective growth or death. However, 94-97\% of all sequences within each recipient pool belonged to OTUs also found in the corresponding transconjugal pools, and an effect of changes in non-participatory OTU cell abundance was excluded by calculating alternative $\delta$-values based on relative abundances after excluding all non-participatory OTUs for each treatment. These corrected $\delta$-values are virtually identical to those calculated for the whole recipient community (Supplementary Figure 3) due to the low abundance of non-participatory OTUs. In addition, such effects would manifest in a consistent increase or decrease in all $\delta$-values across all OTUs within one treatment. For all treatments, $\delta$-values were distributed with a median insignificantly different from 1 , the no-effect level on permissiveness if all OTUs would participate in plasmid transfer (Supplementary Figure 4). Thus, changes in the recipient pool composition did not affect the measured $\delta$-values to a significant degree.

Our experimental conditions resemble the agronomic practice of manure application to soil. Pig manures (especially from piglets) often contain elevated levels of $\mathrm{Cu}$ and $\mathrm{Zn}$ (Nicholson et al., 2003) used as feed additives (Jondreville et al., 2003). These are introduced to soil alongside a high load of fecal bacteria hosting various antibiotic and metal resistance plasmids (Smalla et al., 2000; Zhu et al., 2013). We similarly introduce an enterobacterial exogenous donor strain to a soil bacterial community while simultaneously challenging it with metal stress. However, we remove the physical barriers that would limit the contact between freshly introduced plasmid donors and potential recipients in an intact soil matrix (Dechesne et al., 2005), thus assessing the full potential of the soil bacterial permissiveness.

Under reference conditions, $\sim 1$ out of 15000 soil bacterial cells had the potential to receive and, at least transiently, host plasmid pKJK5, consistent with earlier permissiveness measurements of soil bacterial communities for IncP-1 $1 \alpha$, IncP-1 $1 \varepsilon$ and IncPromA broad-host range plasmids (Musovic et al., 2014; Klümper et al., 2015). Despite stress being commonly associated with increasing bacterial evolvability and promoting gene transfer (Gillings and Stokes, 2012), we here show that community-level plasmid acquisition decreased consistently and significantly (27$100 \%, P<0.05)$ with metal-stress independent of the metal, and even exceeded the degree of growth inhibition. This reduction in permissiveness might be the consequence of a decrease in metabolic status, the result of a specific response of plasmid transfer, plasmid replication or marker gene expression to metal exposure or a combination of these. Higher stressor doses were furthermore associated with a further decrease in transfer frequency. Plasmid transfer frequency reduction, previously documented for $\mathrm{Zn}$ stress (De Rore et al., 1994), might be common across soil bacterial communities for a multitude of different metals. 
In spite of the observed absolute decrease in community permissiveness, several OTUs had a markedly increased permissiveness under stress conditions. For example, several OTUs belonging to the Bacteroidetes phylum had a more than 10-fold increased proportion of recipient cells carrying plasmid pKJK5 after stress treatment. Thus, gene transfer from the enterobacterial host across phyla to the soil indigenous community can increase due to metal stress. This short-term increase might play a crucial role for the dissemination of plasmidencoded antibiotic resistance genes from manure as their original fecal hosts are quickly lost due to competitive exclusion (Estrada et al., 2004). In this way, the soil bacterial community can serve as a long-term reservoir for plasmids as elevated retention of plasmids can be observed under longterm metal stress, even for plasmids not coding for metal resistance (Smets et al., 2003).

Although studied for decades, our current knowledge of metal-bacteria interactions is insufficient to pinpoint the mechanisms that link metal exposure to the observed modulation in permissiveness. Several generic and specific mechanisms of metal stress have been described. The cationic metals used in this study $(\mathrm{Cd}, \mathrm{Cu}, \mathrm{Ni}, \mathrm{Zn})$, as well as the anion arsenite share the toxic mechanism of disrupting iron-sulfur clusters of metallo-enzymes (Hughes, 2002; Macomber and Imlay, 2009; Macomber and Hausinger, 2011; Xu and Imlay, 2012). Metal cations are excreted from bacterial cells as a stress response using efflux systems of similar types (P-type, RND, CDF) (Nies, 1999), while arsenite has its own type of efflux system (A-type) (Nies, 1999). All bacteria have a certain tolerance level to metal stress. Thus, for a given exposure, a gradient of stress levels ranging from sub-toxic to toxic or even lethal conditions can exist within a community (Rensing et al., 2002). Due to the multitude of mechanisms of metal toxicity and resistance present in different bacteria, it is safe to assume that although introduced at the same community growth inhibition doses, each element caused diverse specific short-term stressresponses in individual community members.

Taking advantage of the high-resolution identification of transconjugal OTUs, we demonstrated that stress-induced modifications of permissiveness are indeed unique for each OTU. However, the modified permissiveness of an OTU was generally consistent across most metal stresses. In contrast, the bacterial response to the metalloid arsenic was not as strongly correlated with the four metals. One potential explanation could stem from a connection between the regulation of efflux pumps, which are similar across metal ions but different for arsenite (Nies, 1999), and that of permissiveness.

Furthermore, phylogenetically similar OTUs tended to act similarly in their short-term response to different stresses. The stress-induced regulation of permissiveness thus seems to be taxon-dependent, potentially due to evolutionary conservation, and might well be connected to the regulation of the defense mechanisms against foreign DNA, such as CRISPR-cas or RM systems in the specific phylogenetic groups. While the different regulatory control systems for CRISPR-cas systems are not well-understood (Mojica and Díez-Villaseñor, 2010), specific stress responses can lead to induced expression of CRISPR-cas genes, decreasing the plasmid receipt potential (Perez-Rodriguez et al., 2011).

The expression of RM genes is not constant, but depends on environmental conditions (Bayliss et al., 2006), and diverse stressors can play a role in their regulation (Schafer et al., 1994). The observed phylogenetic conservation holds not only true across the highly correlated heavy metal stresses, but also for arsenic stress, thus further indicating that permissiveness toward plasmids might be directly coupled to different stress responses.

In pure cultures, the ability to uptake foreign DNA changes as a response to stress for specific stressors (Arango Pinedo and Smets, 2005; Pérez-Mendoza and de la Cruz, 2009). Due to the phylogenetic conservation of the stress response, results from single strain experiments might have predictive value based on their phylogeny and for diverse stresses of the same type. However, based on the highly diverse responses across different community members neither single strain nor community averaged analyses suffice to predict the effect of stress on plasmid receipt across complex communities. Our results show that understanding the effect of stress on the ecology of plasmid transfer can only be achieved by examination at both community and individual strain level.

We demonstrated here that the stress-response mechanisms affecting the permissiveness among phylogenetically related bacterial groups are similar and consistent for a variety of different heavy metal stresses. Extrapolation of our results to phylogenetically related groups of bacteria and other stressors might therefore be valid. To further understand the stress-induced modulation of permissiveness, the exact cellular responses remain to be elucidated.

\section{Conflict of Interest}

The authors declare no conflict of interest.

\section{Acknowledgements}

We thank J Magid for access to the CRUCIAL field plot, LK Jensen for technical assistance in the laboratory and SM Milani for assistance in FACS sorting. This work was funded by the Villum Kann Rasmussen Foundation Center of Excellence CREAM (Center for Environmental and Agricultural Microbiology). UK is currently supported through an MRC/BBSRC grant (MR/N007174/1). 


\section{References}

Agersø Y, Wulff G, Vaclavik E, Halling-Sørensen B, Jensen LB. (2006). Effect of tetracycline residues in pig manure slurry on tetracycline-resistant bacteria and resistance gene tet( $M)$ in soil microcosms. Environ Int 32: 876-882.

Arango Pinedo C, Smets BF. (2005). Conjugal TOL transfer from Pseudomonas putida to Pseudomonas aeruginosa: Effects of restriction proficiency, toxicant exposure, cell density ratios, and conjugation detection method on observed transfer efficiencies. Appl Environ Microbiol 71: 51-57.

Bahl MI, Hansen LH, Goesmann A, Sørensen SJ. (2007). The multiple antibiotic resistance IncP-1 plasmid pKJK5 isolated from a soil environment is phylogenetically divergent from members of the previously established $\alpha, \beta$ and $\delta$ sub-groups. Plasmid 58: 31-43.

Bahl MI, Oregaard G, Sørensen SJ, Hansen LH. (2009). Construction and use of flow cytometry optimized plasmid-sensor strains. Methods Mol Biol 532: 257-268.

Bayliss CD, Callaghan MJ, Moxon ER. (2006). High allelic diversity in the methyltransferase gene of a phase variable type III restriction-modification system has implications for the fitness of haemophilus influenzae. Nucleic Acids Res 34: 4046-4059.

Berg J, Brandt KK, Al-Soud WA, Holm PE, Hansen LH, Sørensen SJ et al. (2012). Selection for Cu-tolerant bacterial communities with altered composition, but unaltered richness, via long-term cu exposure. Appl Environ Microbiol 78: 7438-7446.

Brandt KK, Frandsen RJN, Holm PE, Nybrø O. (2010). Development of pollution-induced community tolerance is linked to structural and functional resilience of a soil bacterial community following a fiveyear field exposure to copper. Soil Biol Biochem 42: 748-757.

Campbell JIA, Jacobsen CS, Sørensen J. (1995). Species variation and plasmid incidence among fluorescent Pseudomonas strains isolated from agricultural and industrial soils. FEMS Microbiol Ecol 18: 51-62.

Cases I, de Lorenzo V. (2005). Promoters in the environment: transcriptional regulation in its natural context. Nat Rev Microbiol 3: 105-118.

Corvaglia AR, François P, Hernandez D, Perron K, Linder P, Schrenzel J. (2010). A type III-like restriction endonuclease functions as a major barrier to horizontal gene transfer in clinical Staphylococcus aureus strains. Proc Natl Acad Sci USA 107: 11954-11958.

Dechesne A, Pallud C, Bertolla F, Grundmann GL. (2005). Impact of the microscale distribution of a Pseudomonas strain introduced into soil on potential contacts with indigenous bacteria. Appl Environ Microbiol 71: 8123-8131.

De Gelder L, Vandecasteele FPJ, Brown CJ, Forney LJ, Top EM. (2005). Plasmid donor affects host range of promiscuous IncP-1 $\beta$ plasmid pB10 in an activatedsludge microbial community. Appl Environ Microbiol 71: 5309-5317.

De Rore H, Top E, Houwen F, Verstraete W. (1994). Evolution of heavy metal resistant transconjugants in a soil environment with a concomitant selective pressure. FEMS Microbiol Ecol 14: 263-274.

Estrada IB, Aller A, Aller F, Gómez X, Morán A. (2004). The survival of Escherichia coli, faecal coliforms and enterobacteriaceae in general in soil treated with sludge from wastewater treatment plants. Bioresour Technol 93: 191-198.

Excoffier L, Smouse PE, Quattro JM. (1992). Analysis of molecular variance inferred from metric distances among DNA haplotypes: Application to human mitochondrial DNA restriction data. Genetics 131: 479-491.

Franke AE, Clewell DB. (1981). Evidence for a chromosome-borne resistance transposon (Tn916) in Streptococcus faecalis that is capable of 'conjugal' transfer in the absence of a conjugative plasmid. $J$ Bacteriol 145: 494-502.

Gans J, Wolinsky M, Dunbar J. (2005). Computational improvements reveal great bacterial diversity and high metal toxicity in soil. Science 309: 1387-1390.

Giller KE, Witter E, Mcgrath SP. (1998). Toxicity of heavy metals to microorganisms and microbial processes in agricultural soils: a review. Soil Biol Biochem 30: 1389-1414.

Gillings MR, Stokes HW. (2012). Are humans increasing bacterial evolvability? Trends Ecol Evol 27: 346-352.

Halary S, Leigh JW, Cheaib B, Lopez P, Bapteste E. (2009). Network analyses structure genetic diversity in independent genetic worlds. Proc Natl Acad Sci USA 107: 127-132.

Heuer H, Schmitt H, Smalla K. (2011). Antibiotic resistance gene spread due to manure application on agricultural fields. Curr Opin Microbiol 14: 236-243.

Heuer H, Smalla K. (2012). Plasmids foster diversification and adaptation of bacterial populations in soil. FEMS Microbiol Rev 36: 1083-1104.

Hommel G. (1988). A stagewise rejective multiple procedure based on a modified Bonferroni. Biometrika 75: 383-386.

Hughes MF. (2002). Arsenic toxicity and potential mechanisms of action. Toxicol Lett 133: 1-16.

Jondreville C, Revy P, Dourmad J. (2003). Dietary means to better control the environmental impact of copper and zinc by pigs from weaning to slaughter. Livest Prod Sci 84: $147-156$.

Klümper U, Dechesne A, Smets BF. (2014a). Protocol for evaluating the permissiveness of bacterial communities toward conjugal plasmids by quantification and isolation of transconjugants. In: McGenity TJ, Timmis KN, Nogales B (eds), Hydrocarbon and Lipid Microbiology Protocols, Springer Protocols Handbook. Springer-Verlag: Berlin, Heidelberg, pp 1-14.

Klümper U, Droumpali A, Dechesne A, Smets BF. (2014b). Novel assay to measure the plasmid mobilizing potential of mixed microbial communities. Front Microbiol 5: 730.

Klümper U, Riber L, Dechesne A, Sannazzarro A, Hansen LH, Sørensen SJ et al. (2015). Broad host range plasmids can invade an unexpectedly diverse fraction of a soil bacterial community. ISME J 9: 934-945.

Knezevic SZ, Streibig JC, Ritz C. (2007). Utilizing R Software package for dose-response studies: The concept and data analysis. Weed Technol 21: 840-848.

Kozich JJ, Westcott SL, Baxter NT, Highlander SK, Schloss PD. (2013). Development of a dual-index sequencing strategy and curation pipeline for analyzing amplicon sequence data on the miseq illumina sequencing platform. Appl Environ Microbiol 79: 5112-5120.

Lekfeldt JDS, Magid J, Holm PE, Nybroe O, Brandt KK. (2014). Evaluation of the leucine incorporation technique for detection of pollution-induced community tolerance to copper in a long-term agricultural field 
trial with urban waste fertilizers. Environ Pollut 194: 78-85.

Letunic I, Bork P. (2007). Interactive Tree Of Life (iTOL): An online tool for phylogenetic tree display and annotation. Bioinformatics 23: 127-128.

Lindahl V, Bakken LR. (1995). Evaluation of methods for extraction of bacteria from soil. FEMS Microbiol Ecol 16: 135-142.

Macomber L, Hausinger RP. (2011). Mechanisms of nickel toxicity in microorganisms. Metallomics 3: 1153.

Macomber L, Imlay JA. (2009). The iron-sulfur clusters of dehydratases are primary intracellular targets of copper toxicity. Proc Natl Acad Sci USA 106: 8344-8349.

Mah TFC, O'Toole GA. (2001). Mechanisms of biofilm resistance to antimicrobial agents. Trends Microbiol 9: 34-39.

Mojica FJM, Díez-Villaseñor C. (2010). The on-off switch of CRISPR immunity against phages in Escherichia coli: MicroCommentary. Mol Microbiol 77: 1341-1345.

Musovic S, Dechesne A, Sørensen J, Smets BF. (2010). Novel assay to assess permissiveness of a soil microbial community toward receipt of mobile genetic elements. Appl Environ Microbiol 76: 4813-4818.

Musovic S, Klümper U, Dechesne A, Magid J, Smets BF. (2014). Long-term manure exposure increases soil bacterial community potential for plasmid uptake. Environ Microbiol Rep 6: 125-130.

Nicholson FA, Smith SR, Alloway BJ, Carlton-Smith C, Chambers BJ. (2003). An inventory of heavy metals inputs to agricultural soils in England and Wales. Sci Total Environ 311: 205-219.

Nies DH. (1999). Microbial heavy-metal resistance. Appl Microbiol Biotechnol 51: 730-750.

Norman A, Hansen LH, Sørensen SJ. (2009). Conjugative plasmids: vessels of the communal gene pool. Philos Trans $R$ Soc Lond B Biol Sci 364: 2275-2289.

Pérez-Martín J, de Lorenzo V. (1996). In vitro activities of an N-terminal truncated form of XylR, a sigma 54-dependent transcriptional activator of Pseudomonas putida. $J \mathrm{Mol}$ Biol 258: 575-587.

Pérez-Mendoza D, de la Cruz F. (2009). Escherichia coli genes affecting recipient ability in plasmid conjugation: are there any? BMC Genomics 10: 71.

Perez-Rodriguez R, Haitjema C, Huang Q, Nam KH, Bernardis S, Ke A et al. (2011). Envelope stress is a trigger of CRISPR RNA-mediated DNA silencing in Escherichia coli. Mol Microbiol 79: 584-599.

Poulsen PHB, Al-Soud WA, Bergmark L, Magid J, Hansen LH, Sørensen SJ. (2013). Effects of fertilization with urban and agricultural organic wastes in a field trial - Prokaryotic diversity investigated by pyrosequencing. Soil Biol Biochem 57: 784-793.

Rensing C, Newby DT, Pepper IL. (2002). The role of selective pressure and selfish DNA in horizontal gene transfer and soil microbial community adaptation. Soil Biol Biochem 34: 285-296.

Revelle W. (2014). Psych: Procedures for Personality and Psychological Research, Northwestern University, Evanston, IL, USA, http://CRAN.R-project.org/package $=$ psych Version $=1.6 .6$.

Richardson M. (1993). Epitoxicology Monitoring. Richardson ML (ed). VCH Verlagsgesellschaft: New York, NY, USA, pp 335-343.

Roer L, Aarestrup FM, Hasman H. (2015). The EcoKI type I restriction-modification system in Escherichia coli affects but is not an absolute barrier for conjugation. J Bacteriol 197: 337-342.

Schafer A, Kalinowksi J, Simon R, Seep-Feldhaus AH, Puhler A. (1990). High-frequency conjugal plasmid transfer from gram-negative Escherichia coli to various gram-positive coryneform bacteria. J Bacteriol 172: 1663-1666.

Schafer A, Kalinowski J, Puhler A. (1994). Increased fertility of Corynebacterium glutamicum recipients in intergeneric matings with Escherichia coli after stress exposure. Appl Environ Microbiol 60: 756-759.

Schloss PD, Westcott SL, Ryabin T, Hall JR, Hartmann M, Hollister EB et al. (2009). Introducing mothur: Open-source, platform-independent, communitysupported software for describing and comparing microbial communities. Appl Environ Microbiol 75: 7537-7541.

Seier-Petersen MA, Jasni A, Aarestrup FM, Vigre H, Mullany P, Roberts AP et al. (2013). Effect of subinhibitory concentrations of four commonly used biocides on the conjugative transfer of Tn916 in Bacillus subtilis. $J$ Antimicrob Chemother 69: 343-348.

Shintani M, Matsui K, Inoue J, Hosoyama A, Ohji S, Yamazoe A et al. (2014). Single-cell analyses revealed transfer ranges of IncP-1, IncP-7, and IncP-9 plasmids in a soil bacterial community. Appl Environ Microbiol 80: $138-145$.

Slager J, Kjos M, Attaiech L, Veening JW. (2014). Antibiotic-induced replication stress triggers bacterial competence by increasing gene dosage near the origin. Cell 157: 395-406.

Smalla K, Heuer H, Gotz A, Niemeyer D, Krogerrecklenfort E, Tietze E. (2000). Exogenous isolation of antibiotic resistance plasmids from piggery manure slurries reveals a high prevalence and diversity of IncQ-like plasmids. Appl Environ Microbiol 66: 4854-4862.

Smets BF, Morrow JB, Arango Pinedo C. (2003). Plasmid introduction in metal-stressed, subsurface-derived microcosms: plasmid fate and community response. Appl Environ Microbiol 69: 4087-4097.

Sørensen SJ, Bailey M, Hansen LH, Kroer N, Wuertz S. (2005). Studying plasmid horizontal transfer in situ: a critical review. Nat Rev Microbiol 3: 700-710.

Top EM, Rore H, Collard J-M, Gellens V, Slobodkina G, Verstraete W et al. (1995). Retromobilization of heavy metal resistance genes in unpolluted and heavy metal polluted soil. FEMS Microbiol Ecol 18: 191-203.

Wang Q, Garrity GM, Tiedje JM, Cole JR. (2007). Naive Bayesian classifier for rapid assignment of rRNA sequences into the new bacterial taxonomy. Appl Environ Microbiol 73: 5261-5267.

Webb CO, Ackerly DD, Kembel SW. (2008). Phylocom: software for the analysis of phylogenetic community structure and trait evolution. Bioinformatics 24: 20982100.

World Health Organization (WHO). (2014). Antimicrobial Resistance Global Report on Surveillance. Summary: Geneva, Switzerland.

Xu FF, Imlay JA. (2012). Silver(I), mercury(II), cadmium (II), and zinc(II) target exposed enzymic iron-sulfur clusters when they toxify Escherichia coli. Appl Environ Microbiol 78: 3614-3621.

You Y, Hilpert M, Ward MJ. (2012). Detection of a common and persistent tet(L)-carrying plasmid in chickenwaste-impacted farm soil. Appl Environ Microbiol 78: 3203-3213. 
Yue JC, Clayton MK. (2005). A similarity measure based on species proportions. Commun StatTheory Methods 34: 2123-2131.

Zhao FJ, Ma Y, Zhu YG, Tang Z, McGrath SP. (2015). Soil contamination in China: Current status and mitigation strategies. Environ Sci Technol 49: 750-759.
Zhaxybayeva O, Doolittle WF. (2011). Lateral gene transfer. Curr Biol 21: R242-R246.

Zhu Y-G, Johnson TA, Su J-Q, Qiao M, Guo G-X, Stedtfeld RD et al. (2013). Diverse and abundant antibiotic resistance genes in Chinese swine farms. Proc Natl Acad Sci USA 110: 3435-3440.

Supplementary Information accompanies this paper on The ISME Journal website (http://www.nature.com/ismej) 